\title{
MODEL OF MANAGEMENT BY THE QUALITY OF LIFE OF OBESE CHILDREN
}

D0I: 10.36740/WLek202006115

\author{
Kateryna H. Pomohaibo, Nataliya M. Martynenko, Svitlana H. Usenko \\ KHARKIV NATIONAL MEDICAL UNIVERSITY, KHARKIV, UKRAINE
}

\begin{abstract}
The aim of the work is medical and social substantiation and development the model of management by the quality of life of obese children.

Materials and methods: Material processing was performed by using of mathematic-statistical methods: variance, correlation and regression analysis, mathematical prediction, modelling; the relative, average values and their errors were calculated as well as the predictive coefficients, and the odds ratios, which made it possible to obtain reliable data. Results: It was found that the real prevalence of obesity among children and adolescents in Kharkiv was significantly different from the official statistics in Kharkiv region (15,0 per 1,000 of infant population). The general level of excess weight in 2016 was $151,0 \pm 5,2 \%$.

It was developed a technique for predicting the risk of excess body weight in children based on a heterogeneous sequential recognition procedure, which with $95 \%$ of probability can determine the patient's belonging to a particular risk group.

Conclusions: The model of management by the quality of life for obese children was developed. Offered model of management allows to eliminate the managed factors of development of this pathology, to conduct comprehensive monitoring of the state of children's health, to eliminate certain shortcomings of the health care organization, in particular at the primary level, to raise the awareness of the population on methods of prevention, to apply innovative medical technologies, which in turn will help to improve the quality of life for obese children.
\end{abstract}

KEY WORDS: obesity, overweight, quality of life, risk factors, model of management

Wiad Lek. 2020;73(6):1158-1163

\section{INTRODUCTION}

Topicality of presented theme is obvious. Obesity is one of the serious medical and social problems of the present in view of the increasing prevalence among the population of the majority of countries irrespective of sex, race, and social identity, complex effects on health, increasing the cost of medical care for obese people, decrease of their working capacity and reduction of overall life expectancy [1,2]. Some authors notice that there are evidences of the presence of a link between obesity in childhood and adulthood [3].

Negative impact of obesity on physical as well as psycho-emotional problems (such as depression, anxiety, aggression, and feeling of insecurity) and their consequences (low self-appraisal and social isolation) that affect health and patients' quality of life were investigated $[4,5,6]$.

The importance of this problem is increasing in states with low and medium level of income. Overweight and obesity in those countries are widely spread [7].

The study of obese patients' health status needs comprehensive characteristics in frames of generally recognized techniques of quality of life assessment. In modern medicine as well as in pediatrics this methodology has proven to be a simple, reliable, and sensitive method used both in healthy and ill children of all ages $[8,9]$.

Today, in Ukraine, the quality of life in obese children as a complex research problem has not been investigated yet, and scientifically grounded approach to the application of this methodology in theoretical and practical pediatrics is not formulated, which hinders its widespread adoption.

Therefore, the primary task is to study the features of overweight in children and adolescents through the comprehensive assessment of their health and planning the priority actions to improve the quality of life of obese children. Ensuring the effectiveness and efficiency of appropriate measures requires the application of basic regularities of the management process and the development of a model focused on the optimization of main parameters of quality of life and social adaptation of children with this pathology.

\section{THE AIM}

The aim is to study the way of life of obese children and the state of medical aid for them at the primary level as well as working out and introduction to the medical practice of optimized model of management by the quality of life and social adaptation of obese children.

\section{MATERIALS AND METHODS}

Biblosemantic method was used for study of home and foreign experience in this problem; sociological one - for 
investigation of risk factors, quality of life, conditions of medical aid for children with overweight and obesity; statistical one - for collection, the processing and evaluation of received information; method of prognostication was used for the development of a methodic of forecasting of risk of excess weight and obesity in children and prognostic matrix of quality of life for obese children; conceptual modelling was used for the working out the main components of the model for managing the quality of life of obese children; method of expert assessments to evaluate a valid and developed model for managing the quality of life of obese children. Statistical processing and data registration were carried out using computer statistical software packages Statistica 8, Microsoft Exel. The conclusion of ethical commission of KhNMU recognized methods of investigation adequate for such kind of research.

\section{RESULTS}

Complex medico-social research has revealed and proved the necessity of the working out of an effective management model by the quality of life of obese children. Moreover, low level of registration the incidence of overweight and obesity in the child population, poor health care and the lack of widespread use of complex approaches to assessing the health status of obese patients, which is a cause of late diagnosis of the disease and a significant deterioration in the quality of life of children and needs substantiation of appropriate means of optimizing. Special programme of investigation was developed.

Kharkiv city children's outpatient clinic № 2 and the endocrinological outpatient department of municipal hospital № 2 were the basic institutions for the observation.

At the next stage the prevalence of obesity and overweight in a representative sample of children and adolescents in Kharkiv in 2016 was examined.

General and special relative indicators per 1,000 of infant population were calculated. After that some risk factors of children's overweight and state of their health were investigated with the use of dispersion analysis. The power of influence of factors and the ratio of chances were defined. The identified factors were categorized into major influential factors $3 \%$ or more than $(\eta \geq 3 \%)$ and minor ones with the influence less than $3 \%(\eta<3 \%)$. All the factors were the basic ones for the development of a methodic of prognostication the risk factors for accumulation of excess child's body weight based on a heterogeneous sequential procedure involving parental surveys according to prognosis tables and determining the likelihood of overweight development in children.

Evaluation of the quality of life in children with obesity implies the use of special techniques and carried out in two phases: the first phase was conducted individually written survey of children with obesity created by questionnaire. The second stage involved direct analysis of the quality of life index and limitations of life activity in physical, psycho-emotional spheres, public and everyday life. The relative quality of life index was calculated using a special formula. A model of the main components (life spheres) and a prognostic matrix of the quality of life of obese children were constructed. The individual components of each selected restriction sphere were determined.

At the next stage of investigation the quality of care for obese children was evaluated. The following parameters were studied: the state of the medical-diagnostic process (timeliness of the detection of obesity, completeness of the minimum necessary for the disease diagnostic observations, obtaining recommendations on diet and adequate physical activity, regular observation by specialists) coverage of dispensary supervision, visitation and satisfaction by the results of specialists' activity, and parental awareness of obesity.

Based on the results obtained in the previous stages of the study, at the final stage of the study a model for managing the quality of life of obese children was substantiated and developed.

Evaluation of the effectiveness of the proposed model was carried out through the introduction of some elements of the model and the method of expert evaluation.

In frames of this investigation there was a study of the prevalence of overweight and obesity in children and adolescents in Kharkiv (Ukraine). According to the obtained results, it was determined that the overall prevalence of overweight and obesity was $151,0 \pm 5,2 \%$. It was noted that the level of pathology under study was higher in boys than in girls $164,5 \pm 7,6 \%$ and $136,3 \pm 7 \%$ o relatively.

It was found that obesity was detected in $58,4 \pm 3,4 \%$ o children, there were $43,6 \pm 4,2 \%$ girls and $73,4 \pm 5,3 \%$ o boys out of them. The highest prevalence of overweight and obesity in boys and girls was observed in the 6-9 year-age group $(189,9 \pm 9,6 \% 0)$, and the lowest one was in the group of $14-17$ years $(109,5 \pm 9,0 \%$ ). It was revealed that the prevalence of obesity in boys and girls was the highest in 6-9 year-old children $97,1 \pm 10,1 \%$ o and $59,3 \pm 8,2 \%$ o relatively, lower in the group 10-13 year-old children $73,9 \pm 9,2 \%$ o and $47,5 \pm 6,9 \%$ relatively, and much lower in the group of $14-17$ adolescents $38,8 \pm 7,9 \%$ and $7,3 \pm 5,1 \%$ relatively.

During the assessment of the risks of excess weight in children it was found that 22 risk factors had a significant effect on the development of excess body weight. Biological and social hygienic ones were the main risk factors for the formation of overweight. Socio-economic and psychological ones had a secondary impact on the development of the pathology under study.

The group of biological factors includes family tendency to overweight $(\eta-9 \% ; \rho<0,001 ; \mathrm{OR}=3,5 ; \mathrm{CI}=2,3-4,6)$, burdened heredity for type 2 diabetes and hypertension $(\eta-6 \%$; $\rho<0,001 ; \mathrm{OR}=2,8 ; \mathrm{CI}=2,1-3,7$ ), perinatal (pathological course of pregnancy) $(\eta-3 \% ; \rho<0,001 ; O R=2,1 ; C I=1,6-2,9)$, burdened obstetric anamnesis $(\eta-2 \% ; \rho<0,001 ; O R=2,2$; $\mathrm{CI}=1,5-3,1$ ), and postnatal factors (overweight during the first year of life) $(\eta-3 \% ; \rho<0,001 ; O R=2,2 ; C I=1,7-3,1)$, peculiarities of baby's nutrition in the first year of life (artificial, mixed or early additional feeding) $(\eta-3 \% ; \rho<0,001 ; O R=2,4$; $\mathrm{CI}=1,7-3,3)$. It was defined that among the leading socio-hygienic factors there were poor nutrition (daily consumption 


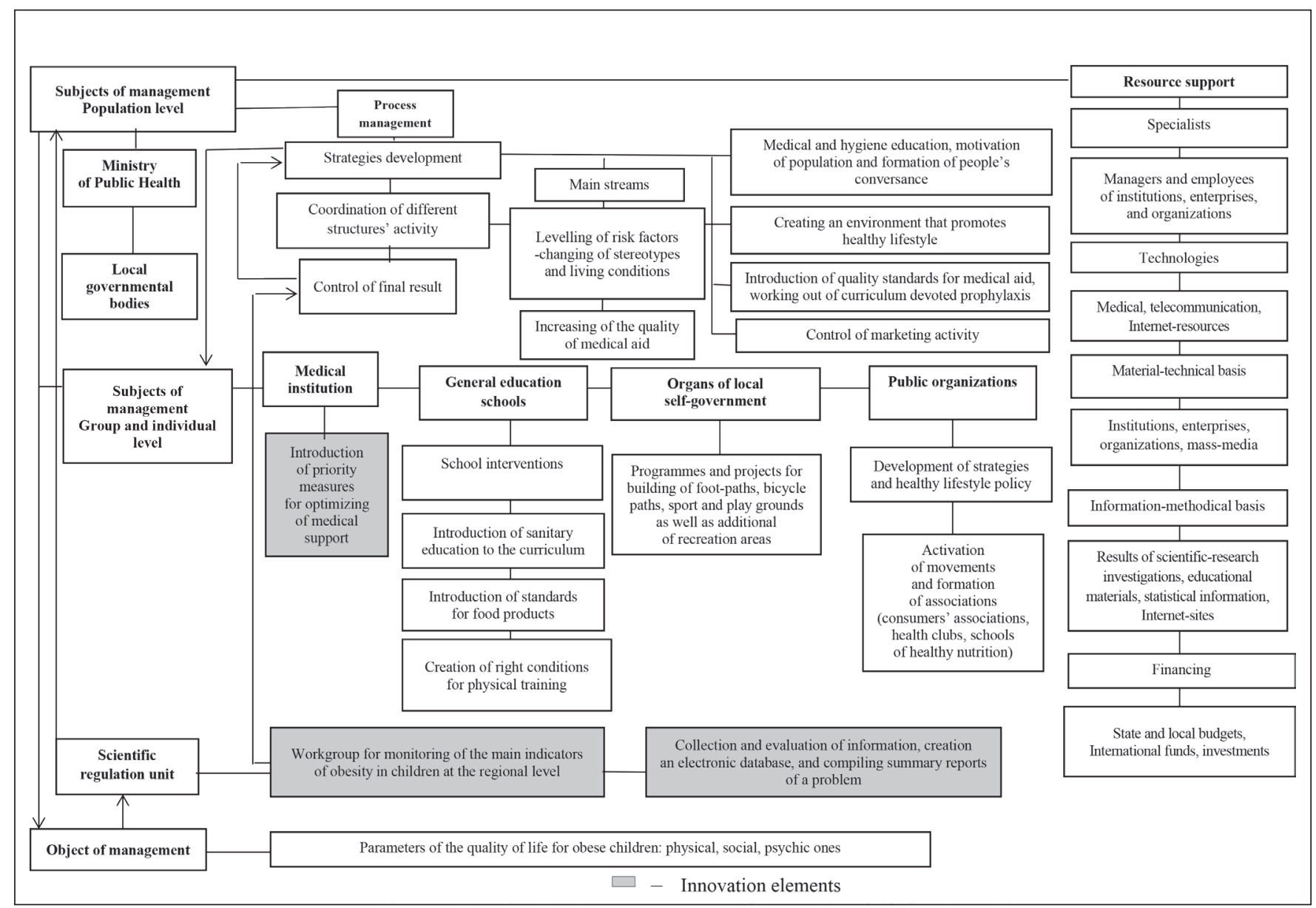

Fig. 1. Functional and structural model of the quality of life for obese children.

of food containing easy digestible carbohydrates and fats) $(\eta-7 \% ; \rho<0,001 ; \mathrm{OR}=3,0 ; \mathrm{CI}=2,2-4,0)$, malnutrition (lack of time and frequency of eating or eating less than three times a day) $(\eta-7 \% ; \rho<0,001 ; O R=3,0 ; C I=2,2-3,9)$, reduced physical activity $(\eta-5 \% ; \rho<0,001 ; O R=2,6 ; C I=2,0-3,5)$, eating a large amount of food $(\eta-5 \% ; \rho<0,001 ; \mathrm{OR}=2,7$; $\mathrm{CI}=2,0-3,6)$, daily e-gadgets stay more than three hours a day $(\eta-4 \% ; \rho<0,001 ; O R=2,2 ; C I=1,6-2,9)$ and visiting fast food businesses more than twice a week $(\eta-4 \% ; \rho<0,001$; $\mathrm{OR}=2,4 ; \mathrm{CI}=1,7-3,4)$.

In the study of the health of children and adolescents with excess body weight and obesity, compared to the control group it was revealed the pathology of the gastrointestinal tract $(37,2 \pm 2,4 \%$ vs. $13,4 \pm 1,7 \% ; \rho<0,001)$, respiratory diseases $(26,3 \pm 2,2 \%$ vs. $9,2 \pm 1,5 \% ; \rho<0,001)$, spine curvature and flat feet $(42,5 \pm 2,4 \%$ vs. $14,6 \pm 1,8 \% ; \rho<0,001)$, hypertension $(31,4 \pm 2,3 \%$ vs. $11,4 \pm 1,6 \% ; \rho<0,001)$, neurological pathology (vegetative dis-regulation, neurosis) $(46,2 \pm 2,5 \%$ vs. $23,4 \pm 2,1 \% ; \rho<0,001)$ was significantly higher in the main group than in the control one.

A method for predicting the risk of developing the overweight among children and adolescents involved interviewing the patient's parents using prognostic tables based on the identified factors and determining the risk of the disease (the first group was the one in which there was not risk of developing excess body weight; the second group with uncertain clinical prognosis; the third one with high risk of overweight).

It was defined that the relative average of the quality of life of obese children and adolescents was $60,7 \pm 0,5 \%$ being in frames from 39,3 up to $90,6 \%$ and corresponded to the average level of variability $(12,9 \%)$. This index was much lower in patients with complicated forms of disease than without such ones and it was $48,3 \pm 1,04 \%$ and $62,6 \pm 0,43 \%$ $(\rho<0,001)$ respectively.

According to the separate analysis of physical sphere components it was defined that the most part of respondents had limitations in performing of heavy physical activity $(67,9 \pm 3 \%)$, moderate exercises $(46,4 \pm 3,2 \%)$, in climbing up the stairs $(56,1 \pm 3,2 \%)$, had complaints for the rapid fatigue $(37,8 \pm 3,2 \%)$, and shortness of breath and heartbeat $(55,7 \pm 3,2 \%)$. It was noticed that the significant impact on the life quality in psycho-emotional sphere had such factors as feeling of anxiety $(39,7 \pm 3,2 \%)$, depression $(41,4 \pm 3,2 \%)$, irritability $(36,3 \pm 3,1 \%)$ and low self-esteem $(51,5 \pm 3,3 \%)$. Among the main factors that limited the quality of life in children and adolescents in social life there were difficulties (misunderstanding) in communication with coevals $(30,4 \pm 3 \%)$, solitude $(22,8 \pm 2,4 \%)$ and lack of attention from surrounding people $(15,6 \pm 2,4 \%)$.

Organization of the medical aid to obese children was also among the big points of this investigation. It was de- 


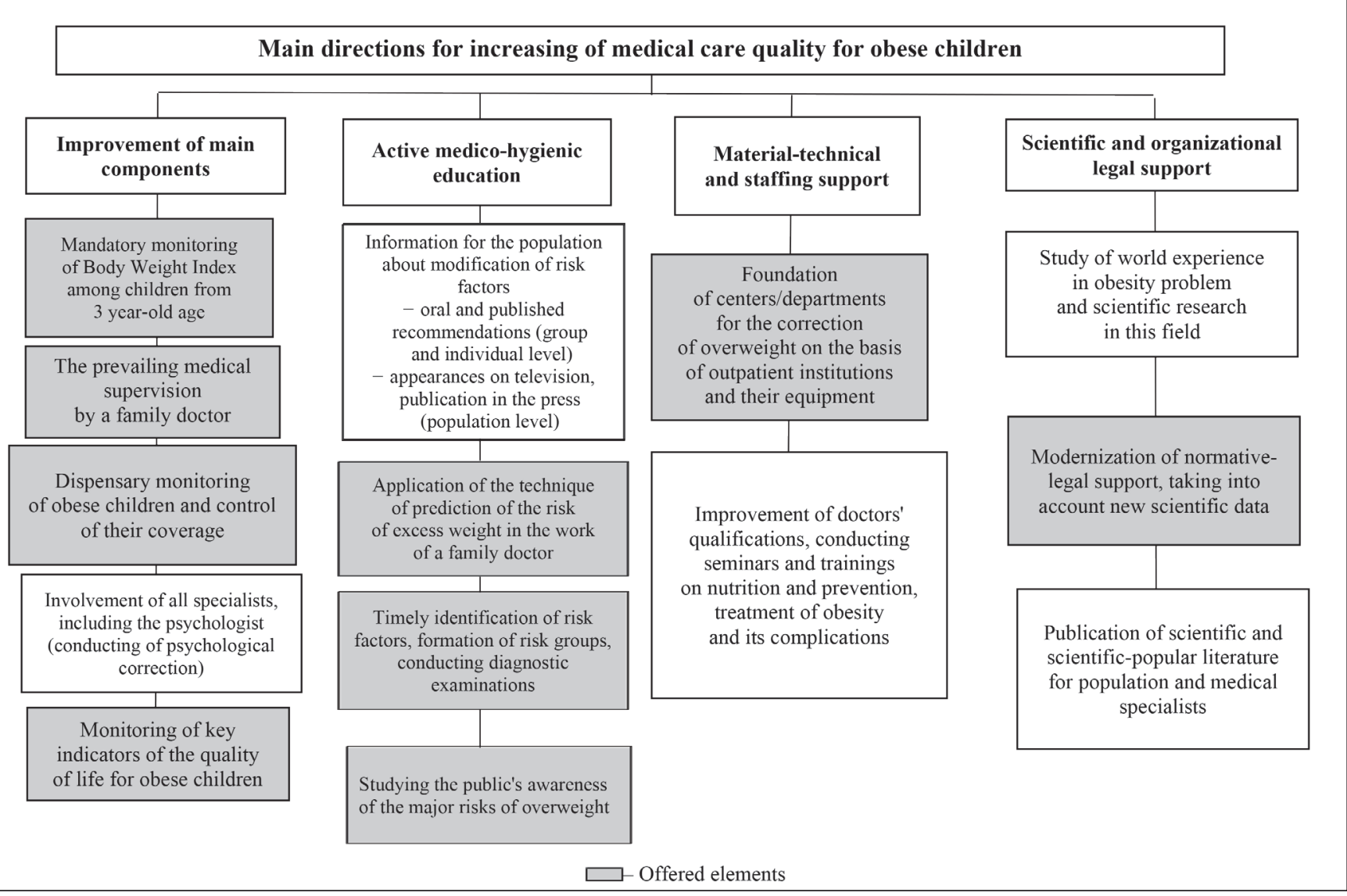

Fig. 2. Components of functional-optimized structure of medical-prophylactic aid for obese children

tected that the diagnosis "obesity" in the child's medical history (form № 112/o) had just 61,7 $\pm 2,7 \%$ adolescents, including $36,1 \pm 2,9 \%$ cases, when this diagnosis was detected after the self-conversion to endocrinologist, and in $14,5 \pm 2,1 \%$ cases of inpatient care. It was found that after the setting of diagnosis $51,4 \pm 3,6 \%$ of children had regularly endocrinological check ups, $35,7 \pm 3,4 \%$ was under the family doctor's observation, $12,9 \pm 2,4 \%$ of children were not observed by any specialist. In $73,4 \pm 2,7 \%$ cases parents got recommendations (written or oral ones) for proper nutrition and adequate physical exercises. In $28,1 \pm 2,7 \%$ cases these recommendations were given by family doctor, in $34,2 \pm 2,8 \%$ cases by endocrinologist or the other specialist and in $11,1 \pm 1,8 \%$ cases by the group of specialists. In $12,9 \pm 2 \%$ cases patients did not have any laboratory examinations $(0 \%) ; 22,8 \pm 2,5 \%$ (25\%) were examined partially; $31,1 \pm 2,8 \%$ and $18 \pm 2,3 \%$ of patients had the half of examinations $(50 \%)$ and nearly the full examination (75\%) respectively. Just $15,0 \pm 2,1 \%$ of children and adolescents had results of minimal examination. The coverage of dispensary surveillance in the study group of children was only $29,6 \pm 2,7 \%$. The structure of referrals to specialists for the disease was presented as follows: 3 and more times to the district pediatrician $21,9 \pm 2,7 \%$ of children and adolescents, to the endocrinologist $34,9 \pm 2,6 \%$, to the cardiologist $16,4 \pm 2,2 \%$, to the gastroenterologist $11,5 \pm 1,9 \%$, to the neurologist $10,9 \pm 1,7 \%$, and to the oth- er specialists $9,4 \pm 1,7 \%$ respectively. It was revealed that according to the questionnaire of parents, the average assessment of the work of the district pediatrician on a five-point scale was 3.7, the endocrinologist and other specialists 4.1 and 3.9 respectively.

According to the results of the investigation the model for managing the quality of life for obese children was developed (Fig. 1). This model consists of the subjects of management at the population level (local governmental bodies at the regional level, Ministry of Public Health, Regional Center of Public Health), at the group and individual levels (health institutions, organs of local self-government, educational institutions and public organizations), a block of scientific regulation (monitoring group of the main indicators of obesity in children at the regional level), the quality of life for obese children and adolescents was an object of management, as well as resource support (specialists, material-technical, information-methodical basis, technologies and financing) included main directions for this problem solution. The main purpose of the management model was the creation the necessary conditions that will help to optimize the quality of life for obese children and adolescents.

Subjects of management at the population level have to plan the main strategies, coordinate the activity of different structures and control them.

Strategies that will improve the quality of life of children with this pathology being investigated, serve as the primary 
management mechanisms should be tailored to the monitoring data (summary reports), use of world experience, standards, recommendations, WHO principles, including preparing and adoption of laws, targeted programmes, and normative basis that cover different sectors (health care, education, agriculture, food industry, catering, trade, marketing, ecological planning, mass-media, etc.).

According to the research it was proved that the initial measures have to be directed on the modification of risk factors namely: changing of stereotypes and habitat that impacts the formation of pathology and increasing of medical care quality. Because of that conducting of medical-hygiene education of population through mass-media, motivation and raising awareness related to healthy lifestyle, formation of stereotypes of the attitude of public health system and the society to obese people, introduction of standards, programmes of prophylactic of non-transmissible diseases, increasing the quality of medical aid, creation of environment that encourages healthy lifestyle (availability of physical activity and healthy food), control of marketing activity (promotion of food sales and non-alcoholic beverages, introduction of standard system of food labeling).

In order to implement the main strategies at the group and individual level, administrative decisions in different fields should be adopted and appropriate optimization measures be planned. This requires the involvement of structures such as local self-government institutions, public health institutions and public organizations.

Health care facilities should be implemented to improve the quality of care. To emphasize the value of the proposed model for the health care system, a functionally optimized structure of care for obese children was identified (Fig. 2).

Effective interaction between main elements of offered model of management can be implemented through the functioning of a monitoring group of key indicators of obesity in children (scientific regulation unit) at the regional level, which should perform the following functions: collection and evaluation the necessary information about obesity (prevalence, eating patterns, physical activity of children and adolescents in different socio-economic groups, quality of life, etc.) using standard techniques, creation a common electronic database (patient registry) and compiling consolidated reports, which provides feedback and enables timely identification of key areas for optimization.

Introduction of some elements of the proposed model into the practical activity of the city children's outpatient clinic №2 in Kharkiv has proved its medical and social efficiency. Thus, during the study period (2016-2018 years), in processing of anthropometric data of a representative sample for children from 6 up to17 years old and calculating the relevant prevalence rates, it was found that the overall prevalence of overweight and obesity among children decreased from $151,0 \pm 5,2 \%$ in 2016 to $142,2 \pm 4,1 \%$ in 2018.

According to experts, the model of quality management of life of children with obesity has the following characteristics: preventive orientation $(9,2 \pm 0,21)$, economic feasibility $(8,34 \pm 0,28)$, compliance with current international experience $(7,9 \pm 0,24)$, efficiency $(8,2 \pm 0,25)$, accessibility $(8,3 \pm 0,26)$, and corresponds to such concepts as complexity and systematic $(8,3 \pm 0,27)$. All the experts (100\%) expressed a positive attitude towards putting the proposed model into practice. The largest number of experts $(85,2 \pm 6,8 \%)$ noted the likelihood of improving the quality and length of life. Major part of experts is convinced that patients and their parents are well-informed $(74,1 \pm 8,4 \%)$ of referrals $(77,8 \pm 8,0 \%)$, and satisfied by the quality of care $(63,0 \pm 9,2 \%)$. According to experts, implementation of management model can enhance efficiency $(74,1 \pm 8,4 \%)$ and rational distribution of workload and efficiency $(66,7 \pm 9,1 \%)$ of healthcare.

\section{DISCUSSION}

Authors achieved the aim. Methodology and complex of measures for investigation were developed. In addition, charts for the copying the necessary information, as well as questionnaires for sociological research and expert evaluation maps of the proposed model were formed. Collection, analysis of received information, computer database and statistical processing of material were carried out. The authors summarized the results of the prevalence of overweight and obesity, taking into account age, sex and complications, risk factors for the formation and development of overweight, quality of life and condition of medical and preventive care for children with this specified pathology, which became the basis for substantiation and development of the model of management by the quality of life of obese children. The results of the study, the scientific provisions and conclusions had been published before. Results of the work are original. In frames of further investigations it is necessary to control body weight in schoolchildren regularly and create an electronic database with constant updating. Each local physician has to be skillful in measuring of body weight and height of patients as well as determining of BMI. It is compulsory to use the integrated approach of medical and non-medical institutions to the formation of healthy environment for obese children. It is compulsory to study the quality of life of such children in dynamics and correct it in the case of necessity. Moreover, it is significant to form the appropriate attitude of society to these children, because it affects their quality of life.

\section{CONCLUSIONS}

Authors worked out the model of management which allows eliminating the factors of development of this pathology. It was also offered to conduct comprehensive monitoring of the state of children's health to eliminate certain shortcomings of the health care organization, in particular at the primary level, to raise the awareness of the population on methods of prevention, to apply innovative medical technologies, which in turn would help to improve the quality of life of obese children. It was defined that biological and social-hygienic factors were the leading ones for the formation and development of overweight in 
children and adolescents. Among the biological ones there was family tendency to overweight and weighted heredity for type 2 diabetes and hypertension, peri-natal and postnatal-factors. In the group of social-hygienic ones there were found poor food, eating disorders, reduced motor activity, overeating, daily use of electronic devices for more than 3 hours, and visits to fast food establishments more than twice a week.

1. It was substantiated and developed a two-staged methodic of estimation of the quality of life of the patients with complicated and non-complicated forms of this disease.

2. It was proved that the medical care of obese children nowadays is not very effective, so the ways of optimizing of medical aid at the primary level are offered, such as compulsory monitoring of body mass index for 3-yearold children and upwards, observation of overweight and obese children by a family doctor, monitoring of health condition for these group of patients, and active complex approach for treatment of such pathology by different specialists (including psychologist), monitoring of the main indexes of the quality of life of obese children, active prophylactic work, adequate technical and staff support as well as scientific and legal provision.

3. The model for management by the quality of life of obese children was developed. It includes the main variants for the solution of this problem. It also has innovation elements for the defining of the significant parameters of the quality of life: physical, psychic and social (object of management); creation of the monitoring group (unit of scientific regulation), which can collect and process the information using standard approaches. Functional-optimized structure of the medical care for obese children was developed.

Introduction of some elements of this model to the practical public health proved their medical and social efficiency. All the experts noticed positive attitude to the introduction of this model to the practical public health.

\section{REFERENCES}

1. Gahagan, S. et al. Overweight and obesity. Nelson textbook of pediatrics (20th ed.). Philadelphia: Saunders/Elsevier. 2016.

2. Todurov I.M., Perekhrestenko 0.V., Kalashnikov 0.0 et al. Prohnozuvannia operatsiino-anesteziolohichnoho ryzyku $v$ bariatrychnii khirurhii za shkaloiu P-POSSUM [For predicting of operative-anesthesia risk in bariatric surgery on a scale P-POSSUM]. International Medical Journal. 2018;24(1):39-42. (In Ukrainian).

3. Nechytaylo Y.M., Kovtyuk N.I. Overweight and obesity in school-age children. Bukovyna Medical Bulletin. 2016;20(3):132-135.
4. Korzun V.N., Harkusha S.L., Bolokhnova M.V. et al. Profilaktyka ta likuvannia ozhyrinnia yak osnovnoi skladovoi metabolichnoho syndromu u naselennia [Prevention and treatment of obesity as a major component of the metabolic syndrome in the population]. Problems of Aging and Longevity. 2015;24(3-4):408-419. (In Ukrainian).

5. Tsyunchyk Yu.H. Klinichne znachennia psykhoemotsiinykh faktoriv pry ozhyrinni u ditei [Clinical significance of psycho-emotional factors in obesity in children]. Modern Pediatrics. 2016;5:98-101. (In Ukrainian).

6. Solnceva A.V., Volk Yu.V. Sakharnyj diabet I tipa i celiakiya v detskom vozraste: osobennosti klinicheskogo techeniya i diagnostiki u pacientov s «dvojnym diagnozom» [Type 1 diabetes and celiac disease in children: clinical features and diagnosis in patients with "double diagnosis"]. Ukrainian Journal of Pediatric Endocrinology. 2017; 1:4-10. (In Russian).

7. Zelinska N.B., Rudenko N.H. Dytiacha endokrynolohiia v Ukraini: statystychni pokaznyky za pidsumkamy 2016 roku ta yikh dynamika [Pediatric endocrinology in Ukraine: statistical indicators based on 2016 results and their dynamics]. Ukrainian Journal of Pediatric Endocrinology. 2017;2:5-17. (In Ukrainian).

8. Styne DM, Arslanian SA, Connor EL et al. Pediatric Obesity - Assessment, Treatment, and Prevention: An Endocrine Society Clinical Practice Guideline. J Clin Endocrinol Metab. 2017;1;102(3):709-757. doi: 10.1210/jc.2016-2573.

9. Chumak L. I., Pomogaybo K. G. Using of medical documents to identify the true prevalence of obesity and overweight in schoolchildren 6-17 years. Inter Collegas. 2015;2(3): 244-252.

This work was realized in frames of scientific-research work "Medical and Social Aspects of Health Monitoring in Students at High School" by Public Health and Healthcare Department (Kharkiv National Medical University), period of realization 2015 - 2017, number of state registration $0115 U 000239$.

\section{ORCID and contributorship:}

Kateryna H. Pomohaibo - 0000-0003-4306-6336 B,C,F

Nataliya M. Martynenko - 0000-0003-3018-2514 A,D,E

Svitlana H. Usenko - 0000-0002-2567-7267 E,F

\section{Conflict of interest:}

The Authors declare no conflict of interest.

\author{
CORRESPONDING AUTHOR \\ Nataliya M. Martynenko \\ Kharkiv National Medical University \\ tel: +380679061569 \\ e-mail: nmartynenko@ukr.net
}

Received: 05.03 .2020

Accepted: 06.05.2020 